\title{
Wallenberg Sendromu'na Neden Olan Vertebral Arter Diseksiyonu
}

\section{Wallenberg's Syndrome Caused by Dissection of The Vertebral Artery}

\author{
Faik Ilik $^{1}$, Huseyin Buyukgol ${ }^{2}$, Ayşegül Öğmegül ${ }^{3}$
}

${ }^{1}$ Mevlana Üniversitesi, T1p Fakültesi, Nöroloji Ana bilim dalı, Konya Türkiye ${ }^{2}$ Aksaray Devlet Hastanesi, Nöroloji Kliniği, Aksaray Türkiye

${ }^{3}$ Necmettin Erbakan

Üniversitesi, Meram Tip

Fakültesi, Konya Türkiye

\section{Corresponding Author:}

Dr. Faik Ilik

\section{Address:}

Mevlana Üniversitesi, Tip Fakültesi, Nöroloji Ana bilim dalı, Konya Türkiye

Tel: $03562129500-1268$

\section{E-mail:}

faikilik@hotmail.com

Başvuru Tarihi/Received : 16-10-2014

Kabul Tarihi/Accepted: 20-11-2014

\section{ÖZET}

Vertebral arter diseksiyonu nadir görülmekle birlikte son yıllarda 45 yaş altı hastalarda sıklıkla tanınan bir inme nedenidir. Hastalarda boyun ağrıs1 ve posterior fossa civarında baş ağrısı görülür. $\mathrm{Bu}$ makalede nadir görülmesi nedeniyle Wallenberg sendromuna neden olan vertebral arter diseksiyonu sunulmuştur.

Anahtar Kelimeler: Vertebral arter diseksiyonu, Wallenberg sendromu, İnme

\section{ABSTRACT}

Vertebral artery dissection (VAD) is a relatively rare but increasingly recognized cause of stroke in patients younger than 45 years. Patients present variably, most frequently with neck pain and headache as well as posterior fossa. In this article we present a case with VAD causes Wallenberg syndrome because of rare presentation.

Key words: Vertebral artery dissection, Wallenberg syndrome, Stroke 


\section{GíRiș}

Wallenberg sendromu lateral medullanın etkilendiği genel olarak duysal bozukluk, tek taraflı horner sendromu ve serebellar bulguların gözlendiği bir hastalıktır. $\mathrm{Bu}$ semptomlarda çeşitlilik gözlenebilir (1). Wallenberg sendromu geleneksel olarak posterior inferior serebellar arter (PICA) tıkanması ile iliskilendirilmiştir. Ancak çalışmalar 10 olgunun 9'unda tıkanan damarın vertebral arter olduğunu gostermiştir (2). Bildirimizde spontan olarak meydana gelen lateral medüller sendrom klinik tablosuna neden olan vertebral arter diseksiyonu sunulmuştur.

\section{VAKA}

Otuz sekiz yaşında erkek hastanın aniden baş ağrısı, bulantı, kusma ve terleme şikayetleri başlamış. Bu şikayetlerine 3-4 saat sonra yutma güçlüğü, hıçkırık, çift görme şikayetleri eklenmiş. Özgeçmişinde son 15 yıldır günde 2 paket sigara içme öyküsü olan hastada bunun dışında belirgin özellik yoktu. Kraniyal Sinir muayenesinde; spontan rotatuar nistagmus, sağ gözde hafif pitoz ve miyozis (Horner sendromu), sağ yüz yarısında hipoestezi ve öğürme refleksinin azaldığı belirlendi. Diğer nörolojik muayene bulgularında ise; sağda serebellar testler beceriksiz, sağda hemihipoestezi solda ise ağrı ve 1sı duyusu bozukluğu tespit edildi. Difüzyon ve Kraniyal MRG'de sağ lateral medullar infarkt infarkt saptandi (Resim 1).Serebral ve kraniyal MR anjiyografi görüntülemesinde sağ vertebral arterde diseksiyona bağlı anevrizmatik görünüm saptanan hastanın tanıs1, 4-damar selektif serebral anjiografi incelemesi ile kesinleştirildi (Resim 2). Antiagregan tedavi (asetilsalisilk asit 300mg/gün) başlanan hastanın şikayetlerinde belirgin düzelme gözlendi. 4 yıllık takibinde yeni bir atak gözlenmedi. Servikal MR anjiyografi takiplerinde anevrizmanın küçüldüğü gözlendi.
Resim 1: Difüzyon MRG'de sağ lateral medullar infarkt görünümü

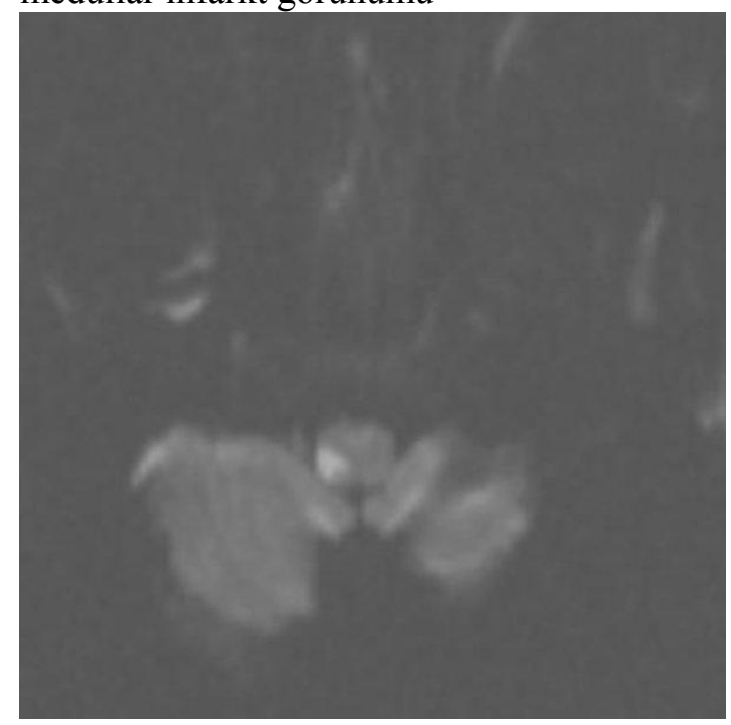

Resim 2: DSA'da să vertebral arterde diseksiyona bağlı anevrizmatik görünüm

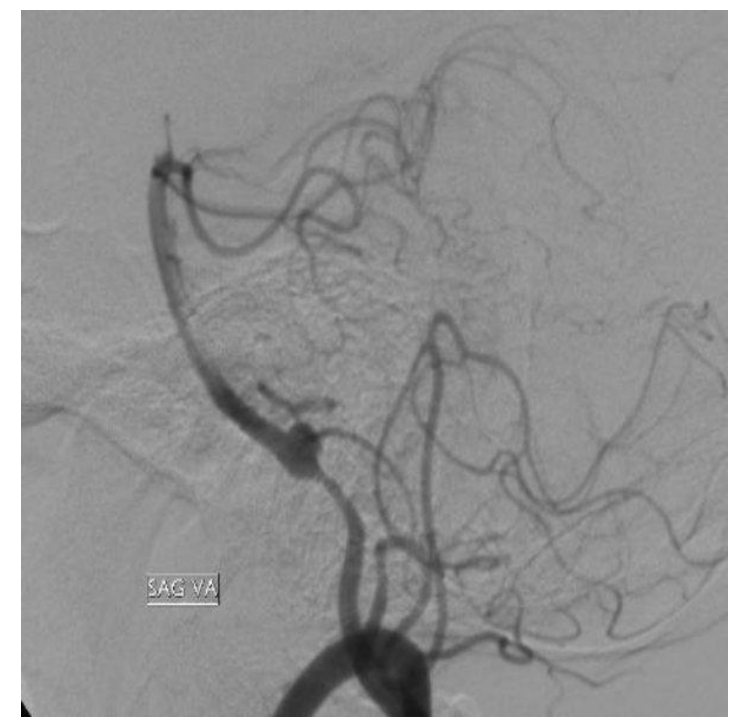

TARTIŞMA

Kırk beş yaş altında tüm inmelerde \%1025 oranında karotis veya vertebral arterlerin diseksiyonu rol oynar. Daha ileri yaşlarda ise bu oran \%2,5'lara inmektedir (3). Ekstrakranial diseksiyonlar sıklıkla 40'lı yaşlarda görülürken intrakranial diseksiyonlar daha genç yaşlarda görülmektedir (4). Serviko-sefalik arter diseksiyonları arter duvarı içersine doğru olan 


\section{DOI: $10.16899 /$ ctd.29759}

kanama sonucu gelişir. Bu diseksiyonlar daha çok karotis sisteminde izlenmekte olup nadir de olsa vertebral arterde de gözlenmektedir. Vertebral arter diseksiyonları çoğunlukla travmaya bağlı olarak ortaya çıkarlar ancak spontan olarak da gelişebilirler (5). Kadınlarda servikokranial arter diseksiyonlarının, özellikle ekstrakranial lokalizasyonda, erkeklere oranla 2.5 kat fazla olduğunun gözlendiği çalışmalar mevcuttur (6). Vertebral arter diseksiyonunun başlangıç klinik bulgusu hastaların yarısında oksipital baş ağrısıdır. Baş ağrısı nadir de olsa tüm başı içine alabilir (7). Hastaların \%60'1 ise vertebrobaziler sistem iskemisini düşündüren bulgularla başvururlar (8). Genellikle baş veya boyun ağrılarından yaklaşık olarak iki hafta içinde iskemi bulguları ortaya çıkar. Vakamızda da önce baş ağrısı şikayeti başlamış ve 3-4 saat sonrasında beyin sapına ait klinik bulgular (yutma güçlüğü, hıçkırık, çift görme) eklenmiştir.

Vertebral arter diseksiyonlarının \%90'nında iskemik bulgular meydana gelir, başta lateral medulla (Wallenberg sendromu) olmak üzere beyin sapı etkilenir. Bunun yanı sira talamus, serebral veya serebellar hemisferlere ait iskemi görülebilir (7). Vakamızın kraniyal sinir muayenesinde; spontan rotatuar nistagmus, sağ gözde hafif pitoz ve miyozis (Horner sendromu), sağ yüz yarısında hipoestezi ve ögürme refleksinin azaldığı tespit edildi.

Diğer nörolojik muayene bulgularında ise; sağda serebellar testler beceriksiz, sağda hemihipoestezi solda ise ağn ve 1 s1 duyusu bozukluğu tespit edildi. Bulgular Wallenberg sendromu ile uyumlu idi. Diseksiyonda oluşan iskemik hasarın mekanizması; damarın ya tamamen daralıp tıkanmasina ya da emboliye ikincil gelişir ve bu dönemde genel olarak antikoagülan tedavi uygulanmaktadır (7).

Vertebral arter diseksiyonu tanısı için non invaziv olmaları nedeniyle sık olarak MR görüntüleme ve Doppler sonografi yöntemleri önerilmektedir. MR görüntüleme ve Doppler sonografide vertebral arterdeki akım anormallikleri genellikle görülebilmektedir.
Ancak lezyonun ne olduğuna karar verebilmek için DSA gereklidir. Arterde akım anormalliğine sebep olabilecek başlıca lezyonlar diseksiyon, mural hematom ve pseudoanevrizmadır. Ayrıca MR görüntüleme akut dönemde yanlış negatif sonuç verebilir. $\mathrm{Bu}$ da özellikle akılda tutulmalıdır (9).

Anjiyografik bulgular değişkendir. Genel olarak bilinen intimal flap ya da çift lümen görünümünün yanı sıra sıklıkla lüminal düzensizlik ya da giderek incelen daralma ve tıkanma izlenmektedir. Distal tromboembolilere bağlı arteryal ani kesilmeler diseksiyonlarda da akut fazda görülebilir (10).

Antikoagülan tedavi diseksiyon nedeniyle ortaya çıkan trombüs oluşumunu engellemek için önerilir (8). Medikal tedavide sık kullanılan tedaviler antikoagülan ve antiagreganlardır. Akut dönemde embolizm riski yüksek olduğu için heparinin başlanabilecek en kısa zamanda verilmesi önerilmekte, tedavi warfarin ile 1-3 ay boyunca sürdürülmektedir. Antikoagülan tedavinin tromboembolik serebral infarktları önlemede antiagregan tedaviden daha etkin olduğu düşünülmektedir. Ancak heparinin, diseksiyon tedavisinde asetilsalisilik asite üstünlüğünü gösterir bir çalışma da henüz yoktur. Bununla birlikte heparin, hemorajik komplikasyon riskini de arttrabilmektedir (11). Özellikle vertebral arter diseksiyonlarının incelendiği bir çalışmada vertebral arter diseksiyonlarının bir kısmının belirgin klinik bulgu vermediği gözlenmiştir. $\mathrm{Bu}$ nedenle gözden kaçtıkları gözlenmiştir. Klinik bulgu verenlerin ise antiagregan ve/veya antiplatelet tedavi ile düzeldikleri bildirilmektedir (12). Hastamıza antiagregan tedavi verilmiş olup şikayetlerinde belirgin düzelme gözlenmiştir.

Vertebral arter diseksiyonlarında prognozun subaraknoid kanama gelişen olgularda kötü olduğu gözlenmiştir. Prognozun kötü olma sebebinin vazospazm olabileceği düşünülmektedir (13). Son zamanlarda vertebral arter diseksiyonlarında perkütan transluminal anjioplasti ve balon oklüzyonu gibi endovasküler tedavilerin yeri tartışılmaktadır. Ancak yeterli çalışma yoktur (14). 


\section{DOI: $10.16899 /$ ctd.29759}

Sonuç olarak arka sistem bulguları ile başvuran genç inmelerde vertebral arter diseksiyonu tanısı özellikle akla gelmeli, bu hastalarda karotis doppler USG ve kraniyal MR'da vertebral arter akım anormallikleri gözlenirse tanı DSA ile kesinleştirilmelidir. Nadir görülen bu tablonun tanısının yeni radyolojik tetkikler ile daha iyi konulabileceği düşünülmektedir. Vakamızda bu tablonun klinik ve radyolojik bulguları, tedavisi ve prognozu tartışılmıştır.

\section{KAYNAKLAR}

1. Day GS, Swartz RH, Chenkin J, Shamji AI, Frost DW.Lateral medullary syndrome: a diagnostic approach illustrated through case presentation and literature review.CJEM. 2014 Mar 1;16(2):164-70.

2. Ropper AH., Brown RH. Adams and Victor's Principles of Neurology. Mc Graw-Hill. (Çeviri Editörü: Murat Emre. Güneş Kitabevi, Ankara, 2006).

3. Schievink WI. Spontaneous dissection of the carotid and vertebral arteries. N Engl J Med 2001;344:898-906.

4. de Bray JM, Penisson-Besnier I, Dubas F, Emile J. Extracranial and intracranial vertebrobasilar dissections: diagnosis and prognosis. J Neurol Neurosurg Psychiatry 1997;63:46-51.

5. Saver JL, Easton JD, Hart RG. Dissections and trauma of cervicocerebral arteries. Stroke. Ed. Barnett HJM, Mohr
JP, Stein BM, Yatsu FM. Second edition. New York, 1992; 671-688.

6. García-Moncó JC, Fernández Cantón G, Gómez Beldarrain M. Bilateral vertebral artery dissection in a patient with afibrinogenemia. Stroke 1996;27:2325-7.

7. Silbert PL, Mokri B, Schievink WI. Headache and neck pain in spontaneous internal carotid and vertebral artery dissections. Neurology 1995;45:1517-22.

8. Chang AJ, Mylonakis E, Karanasias P, De Orchis DF, Gold R. Spontaneous bilateral vertebral artery dissections: case report and literature review. Mayo Clin Proc 1999;74:893-6.

9. Felber S, Auer A, Schmidauer C, et al: Magnetic resonance angiography and magnetic resonance tomography in dissection of the vertebral artery. Radiologe. 1996, 36:872.

10. Zuber M, Meory E, Meder JF. Magnetic resonance imaging and dynamic CT scan in cervical artery dissections. Stroke 1994; 25: 576-581.

11. International Stroke Trial Collaborative Group. The International Stroke Trial (IST): A rondomized trial of aspirin, subcutaneous heparin, both or neither among 19,435 patients with acute ischemic stroke. Lancet 1997; 349:1569-81.

12. Friedman AH: Arterial dissections. In Wilkins RH, Rengachary SS (Eds): Neurosurgery, Second Edition, Vol II. New York, McGraw-Hill, 1996, pp 2173-2176.

13. Han DH, Kwon OK, Oh CW: Clinical characteristics of vertebrobasilar artery dissection. Neurol Med Chir (Tokyo). 1998, 38:107.

14. Higashida RT, Tsai FY, Halbach VV, et al: Interventional neurovascular techniques in the treatment of stroke-state-of-the-art therapy. J Intern Med. 1995, 237:105. 